\title{
PRECISIONES SOBRE RAWLS *
}

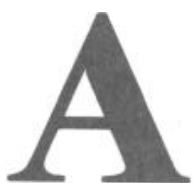

Theory of Justice de J. Rawls supuso a principios de los años setenta la esperanza de que la filosofía política entraba al fin por una vía segura de la que cabía esperar un desarrollo constructivo y sistemático. Quince años después esa esperanza se desvanece de nuevo en manos del propio Rawls. Aunque sólo sea por ello la producción de Rawls merece un análisis detallado en que pueda atenderse a lo sucedido en cada uno de los pasos de una, por cierto, trabajosa, difícil y en ocasiones no poco confusa y tortuosa evolución. Por supuesto que un estudio sobre Rawls no siempre tiene por qué adoptar esa perspectiva y también es cierto que la principal obra de Rawls, A Theory of Justice, es susceptible de lecturas distintas a como Rawls la entiende ahora (Rawls 1985, 233), pero en cualquier caso, la proyección de la evolución de Rawls sobre un único plano, no puede conducir sino a una serie de confusiones que impiden ver lo que la obra de Rawls quiso ser, las dificultades a que se enfrentó y lo que para el propio autor ha resultado de ellas. Con el ánimo de aclarar algunas de estas confusiones, voy a comentar algunos aspectos del artículo «La justificación ética del derecho como tarea prioritaria de la filosofía política. Una discusión desde J. Rawls», publicado por A. Cortina en esta revista.

\section{Dos aclaraciones previas}

En una nota de pie de página del mencionado artículo se lee «En nuestro trabajo nos referiremos a la versión castellana, dado que reproduce en mayor medida la versión inglesa de 1973, que es la más conocida, y además contiene modificaciones efectuadas por el propio Rawls en la versión de Oxford» (pág. 129). Me temo que la autora da por sentado que existe más de una versión de A Theory of Justice. En realidad Rawls no ha mudado ni una coma del texto inglés de su obra, publicada por primera vez en Harvard y reeditada en 1973 en Oxford. La versión castellana de la obra no contiene, pues, «modificaciones efectuadas por el propio Rawls en la versión de Oxford», sino algunas modificaciones al texto original inglés hechas por el propio Rawls para la versión castellana y que sólo aparecen en ésta. Cabe, naturalmente, suponer que Rawls pensaba introducir esas modificaciones al texto en una nueva edición de la obra, pero no llegó a hacerlo. Probablemente la razón fue que las modificaciones tenían que ser tantas, que Rawls pensó más bien en la conveniencia de refundir sus conferencias y artículos posteriores a A Theory of Justice en un pequeño libro ( $\mathrm{El}$ autor espera poder quizá reelaborar todos estos trabajos en un pequeño libro», se dice en la presentación del artículo de Rawls en la edición de las Tanner Lectures de 1981 [Rawls 1982, 21]).

* A propósito del artículo: «La justificación ética del Derecho como tarea prioritaria de la filosofía política. Una discusión desde J. Rawls», publicado por A. Cortina en DOXA, n. ${ }^{\circ}$, 1985 , pp. 129-147. 
Pasemos a una segunda aclaración relacionada asimismo con la producción de Rawls. «Tres etapas cabe distinguir», se nos dice al comienzo del artículo, «en el conjunto de su obra (de Rawls): una amplia fase de gestación, la publicación en 1971 de la Teoría de la Justicia, y la reveladora aparición de esos tres artículos que se congregan en torno al título «The Kantian Constructivism in Moral Theory» (pág. 129). Al no decírsenos de qué es «reveladora» la publicación de «El Constructivismo Kantiano», el lector se queda sin saber por qué ese artículo marca una tercera etapa en la obra de Rawls. Acaso haya que sobreentender que porque en él Rawls introduce por primera vez una importante «serie de cambios de puntos de vista y desplazamientos de acentos» (Rawls, 1985, 224), de revisiones, en suma, de lo dicho en A Theory of Justice. Mas si ése era el sobreentendido, habría sido menester, a mi juicio, mantenerlo presente desde el primer momento, pues parece más que relevante para lo que la autora se propone. En efecto, «en este artículo, añade, no pretendo hacer frente a un libro o a una etapa, sino a la intuición que guía la obra de Rawls, explicitada con mayor claridad en los últimos tiempos» (pág. 129). Esa «intuición» es, según la autora, «el afán de construir una teoría que describa nuestra capacidad moral; o dicho con más precisión, el afán de construir una filosofía moral » (pág. 129). Lamentablemente, el resultado de las revisiones de las que es «revelador» «El Constructivismo Kantiano», explicitadas, en efecto, con más claridad en los últimos tiempos, llevan a Rawls exactamente a la opinión contraria: «Me gustaría subrayar, por fin, que el título de esas conferencias: «El constructivismo kantiano en teoría moral» resultaba engañoso: como la concepción de la justicia de que estamos discutiendo es una concepción política, un mejor título lo hubiera sido «El constructivismo kantiano en filosofía política». La cuestión de si el constructivismo resulta razonable para la filosofía moral es una cuestión distinta y de tipo más general» (Rawls 1985, 224); la misma idea está ya bosquejada en (Rawls 1978, 49) y expresada en términos aún más terminantes en (Rawls 1982, 84-85); y es que la filosofía política de Rawls puede acoger en su seno filosofías morales muy distintas e incluso incompatibles. Otras revisiones llevan a cambios importantes en la articulación de la construcción; así la autora, siguiendo a (Rawls 1980, 527), dice: «Puesto que a nivel nouménico no existen intereses empíricos, los seres nouménicos sólo pueden decidirse a la hora de legislar por intereses morales» (pág. 140); Rawls, en cambio, $(1982,34)$ sentencia: «Nótese que en ningún punto del razonamiento de las partes (en la «posición original»), a éstas les preocupa el desarrollo y ejercicio del sentido de la justicia por mor de él mismo».

\section{La justificación de una «Concepción moral» como «Tarea social práctica»}

Pero pasemos a la cuestión del artículo y de particular importancia para entender la evolución de la obra de Rawls, la de la «justificación práctica». Rawls habla, en efecto, de que la justificación de una concepción de la justicia es una «tarea práctica» más que «un problema epistemológico o metafísico»; en otros momentos habla de que es una «tarea social práctica» (Rawls 1980, 519). ¿Qué quiere decir con ello? 
Ante todo, me parece poco adecuado, e incluso un tanto disparatado, situar la cuestión en el terreno de las idiosincrasias culturales: «Rawls va a adoptar un método de justificación indudablemente anglosajón: recurrir al common sense y prescindir de las justificaciones metafísicas, tan caras al continente europeo... Naturalmente, semejante justificación práctica, anglosajona a todas luces, difiere en algunos aspectos importantes de la validez práctica kantiana, a todas luces germánica, aunque el método rawlsiano de justificación -el «equilibrio reflexivo»- recuerde en algunos de sus pasos la reflexión trascendental kantiana» (págs. 134-135). A mi juicio, el asunto tiene tan poco que ver con idiosincrasias culturales de anglosajones y germanos, que el concepto preciso de lo que la autora llama «validez práctica kantiana» (que, me temo, poco tiene que ver con la tarea social práctica de que habla Rawls) llega a la filosofía moral germana actual desde la filosofía anglosajona. Me explico: en 1981, hablando de Rawls, aunque sin mencionarlo, escribe Hare: «La apelación a intuiciones morales no puede ser nunca suficiente como base para un sistema moral. Ciertamente que es posible, y algunos pensadores de nuestro tiempo lo han hecho, recoger todas las opiniones morales de las que ellos y sus contemporáneos se sienten más seguros, encontrar algún método relativamente simple o aparato que pueda representarse, con un poquito de toma y daca, y hacer supuestos plausibles acerca de las circunstancias de la vida como generadoras de esas opiniones; y después declarar que éste es el sistema moral que, tras haber reflexionado, hemos de admitir como el correcto. Pero no tienen base alguna para esta pretensión allende las convicciones mismas de que partieron, en favor de las cuales no se dio ni una sola razón o argumento. El «equilibrio» que han alcanzado es un equilibrio entre fuerzas que podrían haber sido generadas por el prejuicio; ni por mucha reflexión que pongamos, puede esto convertirse en una base sólida de la moralidad. Dos sistemas que fueran mutuamente inconsistentes podrían ser defendidos entrambos por esta vía; y lo único que ello demostraría es que sus defensores han nacido en distintos entornos» (Hare 1981, 12). Con algo más de indulgencia, pero en la misma vena, y mencionando ya a Rawls, escribe cuatro años después: «Apelando a su propio sentido de la justicia, Rawls llega a conclusiones muy diferentes (de aquellas a que llega Nozick apelando al suyo). Para ser justos con Rawls, él sí tiene, a diferencia de Nozick, un método de razonamiento moral. Pienso que es un buen método y que llegaría a las conclusiones correctas si fuera empleado consistentemente... Pero Rawls vicia su procedimiento apelando continuamente a sus intuiciones morales, que espera que sus lectores compartan. No le basta con estribar sólo en el método... Lo mismo que Rawls, yo pienso que lo primero que hay que buscar son principios de justicia, determinantes de los derechos, que sean aceptables para el pensamiento racional. Pero a diferencia de Rawls, que más bien desprecia toda apelación a la lógica de nuestros conceptos, pienso que la forma de encontrar esos principios es, primero, estudiar nuestro lenguaje y conceptos morales... Esos conceptos y su lógica determinarán para nosotros ciertas reglas que hemos de obedecer al pensar si es que queremos hacerlo racionalmente. Cuando lo hacemos de acuerdo con esas reglas, encontramos que, a la luz de los hechos del mundo en que vivimos, algunos principios de justicia u otros principios morales son 
aceptables, y otros no lo son. Es así como llegamos a nuestros principios de justicia» (Hare 1985, 6-7).

Provistos de esos criterios de moralidad o de justicia podemos enjuiciar expectativas generalizadas de comportamiento (normas) (explícitamente formuladas o no, jurídicamente respaldadas o no, constituidas jurídicamente o existentes con anterioridad a su sanción jurídica), considerándolas legítimas o ilegítimas, y podemos hablar con sentido de que hay expectativas sociales de comportamiento que no debería haber y de que no hay tales o cuales expectativas sociales de comportamiento que debería haber, o refiriéndonos a las acciones podemos hablar, asimismo con sentido, de que una actuación es indefendible por no atenerse a una expectativa de comportamiento que es legítima, o que una actuación que quebranta una expectativa de comportamiento es defendible porque la expectativa que quebranta es ilegítima, y podría ajustarse a otra que no existe, pero que debería existir. Naturalmente, que con estas simplificaciones no pretendo entrar en la cuestión de la distinción entre moral y derecho. Sólo pretendo subrayar lo siguiente: ni los principios son válidos porque su formulación refleje un «estado de cosas» que, por ser un estado de cosas existente, convierta a los principios formulados en «verdaderos», ni las expectativas de comportamiento son legítimas porque su formulación refleje un estado de cosas que por ser un estado de cosas existente convierta a su enunciación en «verdadera», sino que los principios son válidos porque han sido obtenidos conforme a las reglas que nuestros conceptos morales y su lógica determinan, y las expectativas generalizadas de comportamientos son legítimas por ser acordes con esos principios. Dicho de otro modo: nuestros conceptos (y su lógica) relativos a la «regulación de la conducta» definen un ámbito de validez distinto de nuestros conceptos (y su lógica) relativos a nuestras «descripciones del mundo». O en términos de Wittgenstein: que, siendo ambos actividades regidas por reglas, las cuales determinan la aceptabilidad o no aceptabilidad de los resultados, «describir el mundo»y «regular la conducta» son dos juegos de lenguaje distintos. O dicho aún de otra manera: que la función del lenguaje en la que empleamos con sentido los términos «bueno y malo, justo e injusto, legítimo e ilegítimo» es distinta de la función del lenguaje en que podemos emplear con sentido los términos «verdadero y falso». Las normas no son, pues, ni verdaderas ni falsas. Esta idea fue enérgicamente introducida por Stevenson en su crítica a Moore; Stevenson sacó de ella la conclusión (afín a la del positivismo filosófico y jurídico) de que, siendo así, el «razonamiento normativo» carece de reglas lógicas con que decidir sobre su validez, no ocultándose tras él sino un querer y un poder, a lo sumo ilustrados por la ciencia, porque sólo para el lenguaje de la ciencia cabe señalar tales reglas. «El programa de Hare», basado en lo que significaron en el contexto de la filosofía anglosajona filosofías del lenguaje como las de Wittgenstein y Austin, conforme al cual la tarea de la filosofía moral es explicitar la lógica del lenguaje normativo, la lógica de la «validez práctica», ha determinado el desarrollo de la filosofía moral contemporánea desde los años cincuenta.

Lo que por simplificar he llamado «programa de Hare», es decir, las obras de Hare, Baier, Singer, Toulmin, etc. son recibidas en Alemania a mediados de los años sesenta, y determinan los planteamientos de Lorenzen, Schwemmer, Kambartel, Habermas, Apel, Schnädelbach, Wellmer, Tugend- 
hat, etc. Ni siquiera hay que esperar a la filosofía germana para que el planteamiento formulado por Hare en la cita que hemos alegado sea puesto directamente en relación con Kant. De ello se había encargado expresamente Baier, por ejemplo, en los años cincuenta. Ciñéndome sólo a los autores que se citan en el artículo que vengo comentando: Habermas apela directamente a esa tradición, Tugendhat hace otro tanto, Apel no sólo parte de ella, sino que se remonta a tradiciones anglosajonas aún más añejas como es el pragmatismo de Peirce, Wemmer dedica buena parte de su monografía sobre «la universalización en la ética» a la ética normativa que cuaja desde los años cincuenta en el mundo anglosajón, sin encontrar, respecto a la filosofía germana, diferencias dimanantes de diosincrasias culturales, sino una discusión sobre lo mismo en los mismos términos, Alexy en su «teoría de la argumentación jurídica» no encuentra modo mejor de introducir la teoría ética de Habermas, para pasar después a la idea de discurso jurídico como forma especializada del discurso práctico, que partir de los desarrollos de la filosofía anglosajona del lenguaje moral. Naturalmente, entre los autores mencionados existen importantes, y aún decisivas, diferencias en relación con lo que sea la lógica de nuestro lenguaje y conceptos morales y, por consiguiente, en relación con cuáles son y qué estatuto ha de atribuirse a las reglas que han de regir el razonamiento práctico para que el resultado pueda considerarse correcto. Pero en cualquier caso: a) el estudio de nuestros conceptos y de su lógica, que determinan tales reglas es, por supuesto, una tarea epistemológica (en un sentido razonablemente lato de este término) ${ }^{1}$, ¿qué otra cosa podía ser?, y b) las diferencias entre los distintos planteamientos son disputas de familia cuando las comparamos con..., por ejemplo, «el desprecio de Rawls por toda apelación a la lógica de nuestros conceptos».

En efecto, desde el principio Rawls piensa que la cuestión fundamental de la ética es «la de si existe o no existe un procedimiento de decisión para validar o invalidar reglas morales dadas o propuestas y aquellas decisiones tomadas sobre la base de ellas» (Rawls 1951,371), de suerte que las normas y decisiones que resistan la prueba de ese procedimiento puedan considerarse válidas («objetivas», dice Rawls). Con lo que, para entendemos, hemos llamado «programa de Hare» Rawls comparte asimismo la opinión de que la función del lenguaje moral no es describir ni un mundo empírico ni un mundo metaempírico («la cuestión de la objetividad del lenguaje moral no tiene que ver con la cuestión de si existen ideal value entities»), pero de lo que está también seguro es de que la cuestión de si existe o no existe tal procedimiento de decisión poco tiene que ver «con el significado de los términos éticos» (Rawls 1954, 377), nada tiene que ver «con el sentido de las expre-

1 En un sentido en que vendría a coincidir con «teorética». Lo que se entiende por fundamentación de lo que se está diciendo, en obras tales como Principia Ethica de Moore, la Teoría General de Keynes, El lenguaje de la Moral de Hare o los Principia Mathematica de Russel y Whitehead difícilmente podría calificarse como «tarea social práctica». Rawls, como veremos, escoge el término «epistemológico» en su discusión con el intuicionismo racional, al objetar que éste concibe al agente moral como knower (cognoscente), pero es obvio que de ello no se sigue que toda filosofía moral que conciba al agente como agente haya de entender su propia fundamentación como tarea social práctica. 
siones éticas o con su significado lingüístico» (ibid.). Evidentemente, desde el principio Rawls se aparta de la corriente de pensamiento ético contemporáneo que, por citar dos títulos para fijar ideas, va de «El lenguaje de la moral» de Hare a «Conciencia moral y Acción Comunicativa» de Habermas. El caso es que dentro del planteamiento a que se atiene esta corriente, hemos obtenido a lo menos un esquema razonablemente claro de «validez práctica». Como Rawls piensa desde el principio que tal planteamiento no lleva a ninguna parte (y podría tener razón) la cuestión es cómo articular y justificar tal «procedimiento de decisión» (si es que es hallable) y cómo formular respecto a él el correspondiente concepto de «objetividad». En cuanto a lo primero, la respuesta de Rawls desde 1980 es : el establecer un procedimiento ético-político de decisión es una «tarea social práctica».

\section{Una celada al lector}

Por supuesto, que uno puede muy bien compartir el escepticismo de Rawls respecto a la filosofía moral contemporánea, ligada casi toda ella al giro lingüístico, pero antes de tratar de dar sentido a esa expresión de Rawls, se ha de evitar caer en una curiosa celada que en la sección sobre «constructivismo y objetividad» de «El Constructivismo Kantiano» Rawls parece tender al lector, en la que él está muy lejos de caer y que constituye más bien por su parte una estrategia de evitación o parte de un método general, que más tarde llamará «método de evitación» (method of avoidance).

Me parece que la autora del artículo que venimos comentando no la evita. «Los adversarios a los que John Rawls se enfrenta explícitamente -diceson aquellos que dominan el área anglosajona en materia de filosofía práctica - el utilitarismo y el intuicionismo racional» (pág. 132). Naturalmente, el «intuicionismo racional» no domina, junto con el utilitarismo, el área anglosajona en materia de filosofía moral. Tal posición tiene hoy pocos representantes, si alguno. Decir que el intuicionismo racional es hoy dominante en la filosofía moral anglosajona sería tanto como decir que el equivalente del intuicionismo anglosajón, la filosofía de los valores (forma exuberante del intuicionismo anglosajón o, viceversa, el intuicionismo anglosajón forma anémica de la filosofía germana de los valores) domina el área germánica en materia de filosofía moral. En el área anglosajona el intuicionismo es hoy una corriente en todo caso marginal, y desde luego nada significativa en la evolución de la filosofía moral desde los años cincuenta. Y similar es la situación de la filosofía germana de los valores desde, digamos, principios de los años sesenta.

Por supuesto que Rawls lo sabe, y así dice que, supuesta la interpretación que Sidgwick dio de Kant en su Methods of Ethics (1874), «como el planteamiento kantiano es el ejemplo histórico pionero de una doctrina constructivista, el resultado es que el constructivismo no encuentra lugar en los Methods. La situación no cambia si tomamos en consideración otra obra pionera, los Ethical Studies (1876) de Bradley; siguiendo a Hegel, Bradley probablemente consideró la ética de Kant como puramente formal y carente de contenido... El resultado de esas interpretaciones formales de Kant fue que el constructivismo no se reconoció como una concepción moral. Esta 
falta no fue subsanada en la primera mitad de este siglo; pues en este período, empezando por los Principia Ethica de Moore, el interés recayó principalmente en el análisis filosófico y en la trascendencia que ese análisis podía tener para la justificación considerada como un problema epistemológico y para la conclusión de si sus resultados apoyaban o negaban la idea de verdad moral. Durante ese tiempo, sin embargo, el utilitarismo y el intuicionismo hicieron notables progresos. Todavía está por alcanzar una comprensión del constructivismo kantiano que esté a la altura de la idea que tenemos de esos puntos de vista» (Rawls 1980, pág. 556). El autor de A Theory of Justice es aquí un tanto injusto. Pues pase que la filosofía moral kantiana de nuestros días esté muy lejos de alcanzar el grado de articulación alcanzado por el utilitarismo contemporáneo; para convencerse de ello basta estar mínimamente familiarizado con, por ejemplo, la revista Theory and Decision; pero que desde los años cincuenta hasta 1980 en que Rawls pronuncia sus lecciones sobre el «constructivismo kantiano» no hay nada en filosofía moral con un grado de articulación parecido a lo que representan Moore o Ross es sencillamente indefendible. Digamos más bien que Rawls, por de pronto, elude la discusión con esa filosofía moral kantiana; en esas mismas lecciones sobre el «constructivismo kantiano» empezará a hacer de esa evitación virtud, para convertirla clara y decididamente en virtud en los escritos posteriores.

Tras dejar al lector incauto en la celada, Rawls se apresta en «El constructivismo Kantiano» a explicar por qué la tarea de justificar una concepción moral no es una tarea epistemológica, sino práctica. Reducido a un enfrentamiento con el intuicionismo, la parte negativa de la explicación es fácil. Rawls se limita a evocar lejanamente las críticas hechas desde los años treinta a la confusión entre las funciones del lenguaje que son «describir el mundo» (ya se entienda éste como mundo empírico o como un mundo de «ideal value entities») y «regular la conducta». Para el intuicionismo, dice, «los primeros principios de la moral (ya sean éstos uno o varios), cuando se los establece correctamente, son proposiciones autoevidentes acerca de lo que ha de entenderse por buenas razones a la hora de aplicar cada uno de los tres conceptos morales básicos (el del bien, el de lo justo y el de valor moral)» (Rawls 1980, 557). Esta tesis del intuicionismo implica «que el acuerdo en el juicio, que tan esencial es para una concepción públicamente efectiva de la justicia, se funda en la captación de verdades autoevidentes acerca de lo que son buenas razones» (ibid.). Tesis a la que, por cierto, hay que añadir el supuesto psicológico adicional de que «la captación de los primeros principios como verdaderos da lugar, en un ser capaz de intuir racionalmente esos principios, a un deseo de actuar conforme a ellos por mor de ellos mismos» (Rawls, 1980, 560), pues de otro modo no se vería qué tendrían que ver tales principios con nosotros en tanto que «seres capaces de lenguaje y de acción». Resulta, sin embargo, extraño que Rawls no prosiga el razonamiento mostrando la aporética de estas tesis, dirección que históricamente fue la tomada por los críticos del intuicionismo racional en la primera mitad de este siglo; insiste en afirmar que el método constructivista que él adopta, comporta la suposición de que «no existen tales hechos morales, a que los principios adoptados hubieran de aproximarse» y que hubieran de ser objeto de intuición. Mas como esta última afirmación forma 
parte del «programa de Hare» y la elucidación de las reglas a las que ha de obedecer la adopción de principios y normas que puedan considerarse correctos, es desde luego tarea epistemológica, seguimos sin saber qué entiende Rawls por justificación práctica o por justificación de una concepción de la justicia como «tarea social práctica».

No deja de ser sospechoso que en el mismo contexto Rawls se ufane de poder dejar de lado cualquier teoría de la verdad: «Es importante notar que no hay que hacer suposición alguna acerca de una teoría de la verdad. Un planteamiento constructivista no ha menester una explicación idealista o verificacionista, en cuanto opuesta a realista, de la verdad. Sea cual fuere la naturaleza de la verdad en el caso de las creencias generales sobre la naturaleza humana o acerca de cómo la sociedad funciona, lo que una teoría moral constructivista requiere es un procedimiento de construcción claro que permita identificar los primeros principios de justicia. En la medida en que la doctrina moral de Kant depende de lo que a algunos pueda parecerle ser una explicación constructivista de la verdad en la primera Crítica, la justicia como equidad se aparta de ese aspecto del planteamiento de Kant y trata de mantener la estructura general de su concepción moral apartada de ese trasfondo» (Rawls 1980, 566). Digo que tal posición es sospechosa porque el lector (que al leer anteriormente que «el interés recayó principalmente en el análisis filosófico y en la trascendencia que ese análisis podía tener para la justificación considerada como un problema epistemológico y para la conclusión de si sus resultados apoyaban o negaban la idea de verdad moral», antes de caer en la cuenta de la cautela «en la primera mitad de este siglo», había preguntado a Rawls si la última afirmación era también exacta en el caso del análisis ligado a Wittgenstein y a Austin) empieza a barruntar que lo que Rawls no tiene ni pretende tener es un concepto claro de validez, ni teórica ni práctica; sin el trasfondo de la primera Crítica, por ejemplo, Kant no hubiera podido proceder a justificar su «concepción moral» en la tercera parte de la «Fundamentación de la Metafísica de las Costumbres», pues no hubiera podido dar un paso en lo que allí entiende por mostración de las condiciones de posibilidad del imperativo categórico.

Pero la sospecha pasa por una etapa de perplejidad. En un momento, Rawls nos dice que en los razonamientos que ha hecho contra el intuicionismo racional, en realidad «no se ha mostrado que el intuicionismo racional sea falso ni que no pueda constituir una posible base para el necesario acuerdo en nuestros juicios de justicia» (Rawls 1980, 570). La intención del autor sólo fue «definir el constructivismo kantiano por contraste con el intuicionismo, pero no defenderlo, ni mucho menos argumentar que el intuicionismo racional estuviera equivocado. En todo caso, el constructivismo kantiano sólo tiene por fin establecer que la noción de objetividad del intuicionismo racional es innecesaria para la objetividad» (ibid.). Perplejidad por partida doble: el lector familiarizado con las éticas kantianas de la actualidad sabe muy bien que la noción de «objetividad» del intuicionismo (los principios morales son verdaderos porque reflejan la captación de «ideal value entities») no es menester, como queda dicho, para la «objetividad» (validez práctica) de los juicios morales, pero había supuesto que esto era así sencillamente porque el intuicionismo racional era una doctrina equivocada o falsa, y porque además contaba con una manera alternativa de explicar razona- 
blemente los conceptos de «objetividad» o validez práctica»; y segundo, porque al leer en las páginas anteriores que «para Kant el intuicionismo racional era también heterónomo... pues la idea kantiana de autonomía exige que no exista tal orden de objetos dados, que determinen los principios de lo correcto y lo justo entre personas morales libres e iguales», el lector había entendido que Rawls por su parte entiende esta objeción de Kant como una correcta objeción contra el intuicionismo, lo que supone que el intuicionismo racional es indefendible, lo que, a su vez, aproximadamente puede querer decir: que el intuicionismo es una teoría equivocada o falsa. Pues si no, el que nos mostremos poco propensos a aceptar una ética que no sea autónoma, sería problema a cargar a cuenta de nuestros prejuicios; ya Aristóteles, precisamente en su teoría ética, se había visto en el trance de tener que escoger entre Platón y la verdad.

La perplejidad se convierte en decepción cuando el lector vuelve hacia atrás y oye a Rawls interpretar la muy correcta afirmación (que aquí no nos ocupa) de que una doctrina kantiana de la autonomía «no necesita negar que los procedimientos por los que se seleccionan los primeros principios son sintéticos a priori». Pero «esta tesis, añade Rawls, es menester interpretarla adecuadamente. La idea esencial es que tales procedimientos han de estar adecuadamente fundados en la razón práctica, o, más exactamente, en nociones que caractericen a las personas como razonables y racionales y que sean parte integrante de la forma en que, como tales personas, se representan a sí mismas su personalidad moral libre e igual» (Rawls 1980, 559). Habida cuenta de que por esto último simplemente hay que entender las «deep-seated convictions and traditions» vigentes en un estado democrático moderno, el «más exactamente» no pone exactitud en nada, simplemente denota que Rawls no tiene un concepto de razón práctica, lo toma, a lo sumo, prestado de Kant sin revalidarlo. Y ahora entiende el lector la afirmación con que se abre la discusión acerca de la objetividad de la concepción moral que Rawls sustenta: «Esta explicación de la objetividad implica que... los principios de justicia (propuestos) son los más razonables para nosotros, dada nuestra concepción de las personas como libres e iguales y como miembros plenamente integrados de una sociedad democrática» (Rawls 1980, 554). Es decir, el autor parte de un «prejuicio cultural» al que no se somete a prueba ni a revalidación. Lo único que pretende es que, dado ese «prejuicio», los principios que propone constituyen su explicitación más plausible, y es a esto a lo que Rawls llama «objetividad», objetividad por tanto que no tiene nada, absolutamente nada que ver, ni con el concepto kantiano de validez práctica ni con el concepto de validez práctica de las éticas kantianas de la actualidad. Por otro lado, la construcción no puede tener más valor que el prejuicio de que se parte, prejuicio en favor del cual, como escribe Hare, «no se ha dado ni una sola razón». Ahora bien, Hare, Baier, Habermas, Tugendhat, etc., al analizar los conceptos, al hacer afirmaciones sobre la estructura del lenguaje, al determinar las reglas que la lógica de esto o aquello implica, etc., no pueden menos de pretender estar en lo cierto, lo que aproximadamente puede querer decir: de tener una teoría que es verdadera. Una teoría, empero, que sabe que no tiene más valor que el «prejuicio» de que parte, pues que confiesa no revalidarlo, y al que en «The Kantian Constructivism», frente a A Theory of Justice, se acaba incluyendo en 
la propia construcción, no puede presentarse «with a claim of truth» (con una pretensión de verdad). Ahora bien, una teoría que no pretenda ser verdadera, no es una teoría. Pero si A Theory of Justice, tal como el autor la entiende desde «The Kantian Constructivism», no pretende ser verdadera, ¿qué pretende ser entonces? Pretende convencer a los ciudadanos de las sociedades democráticas de que, dada la comprensión que tienen de sí como iguales y libres, pese a las diferencias que los dividen acerca de cómo traducir a instituciones básicas tal comprensión, escarbando en ella es posible encontrar una base de acuerdo que pueda resultar aceptable para todos. A Theory of Justice, «as I understand it now» dice Rawls, no pretende ser verdadera, sino política, una tentativa de allanar profundas desaveniencias. De ahí que la justificación de la concepción que Rawls propone no sea una justificación epistemológica, sino «una tarea social práctica», es decir, política. Y por supuesto, algo que no se presenta con la pretensión de ser verdadero, sino sólo con la pretensión de allanar diferencias, «with a political claim», en suma, queda aquende la cuestión de relativismo o no relativismo.

\section{Mirada hacia atrás y nueva perspectiva}

Recordemos de nuevo la formulación original del programa de Rawls (1951). La cuestión fundamental de la filosofía moral es la de «si existe un método razonable para validar o invalidar reglas morales dadas o propuestas y las decisiones tomadas sobre la base de ellas. Pues decir que el conocimiento científico es objetivo es decir que las proposiciones en que se expresa puede evidenciarse que son verdaderas mediante un método razonable y fiable, es decir, por las reglas y procedimientos de lo que podemos llamar «lógica inductiva»; similarmente, para establecer la objetividad de las reglas morales, y las decisiones basadas en ellas, tenemos que contar con un procedimiento de decisión que sea a la vez razonable y fiable, por lo menos en algunos casos, para poder decidir sobre reglas morales y líneas de conducta atenidas a ellas... podemos concebir la ética como algo más próximo al estudio de la lógica inductiva que a cualquier otro tipo de investigación. Así como en lógica inductiva, de lo que se trata es de descubrir criterios razonables que, cuando nos encontremos con una proposición o con una teoría, junto con la evidencia empírica que la respalda, nos permitan decidir en qué medida debemos considerarla verdadera, así también en ética tratamos de encontrar principios razonables que, cuando nos encontremos con una propuesta de línea de conducta y con la situación en que ha de ponerse por obra, y con los intereses relevantes a que afecta, nos permita determinar si debemos o no traerla a ejecución y sostener si es justa o correcta» (Rawls 1954, 371-372).

Pues bien, hace unos años, al dar vueltas y más vueltas a $A$ Theory of Justice, al preguntarse en qué se asentaba en definitiva toda aquella construcción fijándome sobre todo en conceptos tales como «objetividad», «validez normativa», justificación, explicación, etc. creí darme cuenta de que todo ello constituía en Rawls un laberinto, que, o se desmontaban metódicamente sus piezas para ver qué contenían o uno se perdía irremediablemente en él. En un artículo titulado «La estructura inconsistente de $A$ Theory 
of Justice» creí poder responder que en la ejecución de su programa inicial Rawls había emprendido un camino equivocado; había adoptado un concepto de «explicación», no abandonado, sino potenciado en A Theory of Justice, que estaba muy lejos de ni siquiera poder empezar a dar razón de nuestro sense of justice; que la brillante construcción que es la «posición original» no era en definitiva más que una construcción especular que, en efecto, explicita lo que son nuestras convicciones sobre los problemas de justicia, pero sin poder decidir en ellas lo que es razón y lo que es prejuicio; que, sin embargo, Rawls, estribando en Kohlberg, sí que iniciaba en esa obra una genuina explicación o teoría de nuestro sentido de la justicia, porque llegaba a una explicación que sólo valía para las «sociedades bien ordenadas», sin que llegara a saberse qué tenía que ver ese sentido de la justicia cuya explicación genética se daba (interpretando a Kohlberg) para las sociedades bien ordenadas, con nuestro sentido de la justicia; la teoría de la justicia se ensimismaba; que en vista de estas dificultades, que el propio Rawls percibía, en lo que en verdad Rawls estribaba y a lo que de verdad recurría era a la «interpretación kantiana de la posición original», la cual, sin embargo, en A Theory of Justice era una pieza independiente y aun extraña; independiente, porque en realidad a Kant no se le revalidaba; y extraña, porque al concebirse la teoría de la justicia como parte de la teoría de la decisión racional y, consiguientemente, al definirse a las partes como provistas sólo de racionalidad económica, la «interpretación kantiana» no era sino un aura que envolvía a la situación original haciendo plausibles sus características como situación en que las partes habían de decidir, sobre todo el «velo de ignorancia», pero no algo que pudiese integrarse en la construcción, pues mezclar a Kant con la teoría de la decisión racional era pretender mezclar el agua con el aceite.

Cuando apareció el artículo «The Kantian Constructivism» me sentí confirmado en esa interpretación y en el prólogo a un pequeño libro en que apareció dicho artículo escribí: «En nuestro estudio insistíamos en que a lo largo de A Theory of Justice la interpretación kantiana se convertía en una premisa independiente y con peso propio a la que tenía que apelarse siempre que en el razonamiento se invocaba explícitamente la posición original, pues ésta pendía enteramente de aquélla, y más en concreto, insistíamos también en que la deseabilidad categórica de que se dotaba a la primera serie de bienes primarios (libertades), o era arbitraria o dependía también por entero de aquella interpretación. Pues bien, así es. Si el lector entendió, como es mi caso, que la posición original, junto con nuestro sense of justice que era la base de la explicación, representaban para Rawls elementos capaces de sostenerse a sí mismos con independencia de la interpretación kantiana, o Rawls se explicó mal o el lector entendió peor, aunque parece que en «The Kantian Constructivism» Rawls parece dispuesto a repartir equitativamente entre el autor y el lector la responsabilidad del malentendido» (Jiménez, 1983, 8). Y como por supuesto las convicciones a que se acomoda la concepción kantiana de la persona es algo que se considera dado, en el mismo prólogo concluía: «En algún momento afirma Rawls que «la tarea real de justificar una concepción de la justicia no es primariamente una tarea epistemológica», sino una tarea práctica; se trataría primordialmente de hacer frente al desacuerdo que existe en nuestras sociedades democráticas sobre principios 
de justicia. Pero esto es hacer de la necesidad virtud; pues no veo cómo podría quedar afianzado nuestro «sentido común moral» en momentos en que se siente «dudoso e inseguro» con sólo recordarle las convicciones de las que se siente dudoso e inseguro. Es posible que también en asuntos de «filosofía práctica» nada haya más práctico que una buena teoría. Y es esto lo que no puede proporcionar Rawls» (ibid.). Sin necesidad de retirar ni una palabra de este juicio, me parece, sin embargo, que se basa en un razonamiento implícito que a la luz de los artículos posteriores a «El Constructivismo Kantiano» creo que es falso; este razonamiento implícito podría explicitarse del siguiente modo: «Puesto que Rawls se ve obligado en definitiva a acogerse a Kant sin contar al cabo con elementos conceptuales suficientes con que poder validarlo, recurramos a la teoría ética contemporánea cuya principal preocupación es precisamente validar a Kant, pues sean cuales fueren las ventajas que ofrece la discusión de contenidos que Rawls lleva a cabo, ésta siempre podrá seguirse desarrollando en el contexto de aquellas teorías; las cuales ofrecen además la ventaja de evaluar la construcción de Rawls; no entiendo, pues, a qué viene tanta alharaca en torno a cosa tan desprovista de base como es esta obra».

Pero ante la vacuidad de las revalidaciones contemporáneas de la ética kantiana (pese a todas las recetas para darles contenido histórico y de actualidad mediante «génesis fácticas» y las correspondientes «génesis normativas» (Lorenzen), que están aún por hacer, o construyendo «ciencias críticoreconstructivas», por ejemplo, una «Ideologiekritik» (Apel), que no se sabe de verdad qué forma podrían adoptar hoy, pues las del pasado se hallan en estado más bien precario; o ante el expectante escepticismo que no pueden menos de producir la magnitud y lo arduo de los programas de teoría sociológica en los que hoy se inserta o con los que se articula la renovación de la ética kantiana cuando de verdad quiere empezar a servir para algo (pienso sobre todo en Habermas), creo que este razonamiento no es sostenible. Supone, en efecto, que $A$ Theory of Justice debe medirse por la formulación de aquel programa inicial y que, por este lado, otros han hecho mucho mejor lo que Rawls pretendía hacer. A la luz de «El Constructivismo Kantiano» y de los artículos que le han seguido, me parece que queda claro que Rawls piensa que no necesita medir su obra con esa pretensión inicial, sino que puede correctamente decir que ahora puede entender las cosas de otra manera y que $A$ Theory of Justice perfectamente se acomoda a este nuevo entendimiento. Expresando las cosas un tanto abruptamente: Rawls puede decir que no ha pretendido desarrollar ni una teoría ético política ni una filosofía moral de la que aquella pudiera ser parte, sino una «concepción política» (Rawls) que se acomode a la autocomprensión que tienen de sí los miembros de las sociedades democráticas y contribuya a allanar las diferencias acerca de cómo pueda traducirse a instituciones tal comprensión.

Pero, ¿no es esto lo de sobra sabido acerca de Rawls? Sí, pero con tal que se saquen las consecuencias de ello, que no solemos sacar, pues propendemos a reabsorber de nuevo a Rawls en lo que Rawls no quiere ser. Esa intención hay que tomarla como punto de partida, por así decirlo, absolutamente primero, por detrás del cual no puede preguntarse a la obra, porque no es sólo que ésta no tenga medios para responder, que no los tiene, sino que adredemente elude el tenerlos. Rawls -y esto no puede menos de resultar 
atrayente- pretende, supuesta la comprensión que de sí tienen los miembros de las sociedades democráticas, poder construir para éstos un marco de razonamiento en que sea posible la discusión ético-política y la «autoaclaración». El punto de Rawls está en decir que de poseer aquellos elementos que le acusamos de no poseer, no podría construir ese marco. Acusar a Rawls de no contar con aquellos elementos, como fue mi caso, pienso que es malentenderlo, al menos tal como éste ve su obra a partir de «El constructivismo Kantiano»; suponer que los tiene y querer poner su obra a la par de la filosofía kantiana contemporánea, como una modalidad más de ella (como pudieran ser la de Hare, Baier, Habermas, Apel, Tugenhat, etc...), es perderse en un laberinto de confusiones, pues implica atribuir a Rawls lo que este expresamente no quiere ser. Voy a tratar de hacer plausibles estas afirmaciones, para pasar después al artículo que vengo comentando.

\section{Aviso al filósofo político: sea superficial, filosóficamente hablando}

Antes he mostrado una cierta perplejidad retórica porque Rawls daba la espalda al «intuicionismo racional», dejando de lado que fuera verdadero o no y se acogía a lo que entendía por «constructivismo» de Kant, sin que ello significara «defenderlo». Pues bien, estas afirmaciones hay que tomarlas tal cual están hechas. «Trato de evitar las controversias filosóficas siempre que sea posible y busco la forma de eludir los prolijos problemas de la filosofía. Así, en lo que he llamado constructivismo kantiano, trato de evitar el problema de la verdad y la controversia entre realismo y subjetivismo acerca del status de los valores morales y políticos» (Rawls, 1985,230). Y es que «no podemos pedir demasiado de una concepción de la justicia». «Una teoría de la justicia cumplirá su papel social, con tal que personas igualmente conscientes y que compartan a grandes trazos unas mismas creencias, si aceptan el marco de deliberación erigido, lleguen normalmente a una suficiente convergencia de juicio necesaria para poner en obra una efectiva y equitativa cooperación social. Mi discusión acerca de las libertades básicas hay que verla a esta luz» (Rawls 1982, 84). La teoría de la justicia va dirigida «a los ciudadanos en un régimen constitucional. Les ofrece una manera de concebir su común y (constitucionalmente) garantizado status como ciudadanos iguales y libres y trata de conectar una particular comprensión de la libertad y la igualdad con una particular concepción de la persona, afín a las nociones compartidas y a las convicciones esenciales implícitas en la cultura pública de una sociedad democrática» (ibid., 85). Pero ha de quedar bien claro que «el papel de una concepción de la persona en una concepción de la justicia política es distinto de su papel en un ideal personal o asociativo, o en una forma religiosa o moral de vida» (ibid., 85), o incluso en una «teoría moral comprehensiva». En una concepción política de la justicia se supone, primero, «que las personas se conciben a sí mismas, y mutuamente, en posesión de la capacidad moral de tener una concepción del bien... Segundo, que los ciudadanos se consideran libres en que se ven a sí mismos como «selforiginating sources of valid claims»..., y tercero, que son considerados capaces de responsabilizarse de sus fines» (Rawls 1985, 243). Mas es esencial subrayar «que los ciudadanos pueden mirar sus asuntos personales o, en la vida interna de las asociaciones a las que pertenecen, pueden muy 
bien mirar sus fines últimos y sus vinculaciones de forma muy distinta que la implicada por la concepción política» (ibid., 241). Pretender otra cosa sería confundir la concepción política de la justicia con «una teoría moral general» sin percatarse de que «la concepción de la justicia como ideal moral comprehensivo sería incompatible con otras concepciones del bien, con otras formas de vida personal, moral y religiosa, consistentes con la justicia y que, por tanto, tienen adecuado lugar en las sociedades democráticas. Como ideales morales comprehensivos la autonomía (Kant) y la individualidad (Mill) son inadecuados para una concepción de la justicia. Tal como los exponen Kant y Mill son ideales morales conprehensivos que, pese a su gran importancia en el pensamiento liberal, van demasiado lejos cuando se los presenta como el único fundamento apropiado para un régimen constitucional. Cuando se lo entiende así, el liberalismo no es sino una doctrina sectaria más» (ibid. 246). Pues, aún suponiendo que Kant y Mill tuvieran en sus teorías morales toda la razón del mundo, la concepción rawlsiana de la justicia «no se basa en toda la verdad, si por toda la verdad han de entenderse las verdades de la religión y de la filosofía, de la doctrina moral y la doctrina política. Por definición, en una sociedad bien ordenada bajo condiciones modernas, no puede haber acuerdo durable sobre estas materias; esta estipulación figura entre las circunstancias subjetivas de la justicia» (Rawls 1980, 542) y si se pregunta por qué han de suponerse tales circunstancias, la respuesta es que «no pueden superarse sino por el uso de la fuerza». «No hay pues alternativa sobre la que fundar una concepción de la justicia adecuada para una sociedad democrática bien ordenada, sino en una parte de la verdad, y no en toda la verdad, o dicho más específicamente, precisamente en las creencias que de hecho comúnmente aceptamos y compartimos» (ibid. 542), que, por cierto, no siempre tienen por qué ser ni siquiera parte de la verdad.

Pero esta respuesta «práctica» 0 «justificación práctica» no significa «escepticismo o indiferencia acerca de las cuestiones religiosas, filosóficas o morales. No digo que sean todas dudosas o falsas, o que versen sobre cuestiones que no son susceptibles de verdad o de falsedad... lo que digo es que no cabe esperar un acuerdo consistente acerca de ellas... y por tanto no cabe esperar un acuerdo razonado y duradero acerca de ellas... A Theory of Justice trata de construir una concepción de la justicia que parta de que estas diferencias profundas e irresolubles sobre materias de fundamental importancia son condición permanente de la vida humana» (ibid. 542). En efecto, la justificación (práctica) de por qué el «velo de ignorancia» excluye que los ciudadanos sepan qué creencias van a tener es porque los principios obtenidos «han de servir como punto de vista compartido para allanar diferencias entre ciudadanos con convicciones filosóficas, religiosas y morales opuestas, así como con distintas concepciones del bien, y ese punto de vista necesita ser adecuadamente imparcial para con esas diferencias» (ibid. 543).

Y si se objeta que ese «punto de vista» que A Theory of Justice busca y pretende haber hallado, al no reclamar como base «verdad» averiguada alguna, no es en definitiva más que un modus vivendi «que permite a cada grupo, en el consenso resultante, perseguir su propia concepción del bien ateniéndose a ciertas ligaduras que cada uno piensa que en definitiva redundan en su propio beneficio, dadas las circunstancias existentes» (Rawls 1985, 247), Rawls, enfrentado a la bien correcta autocomprensión utilitarista de 
la nueva «teoría económica de la sociedad» basada en las «ciencias de la decisión racional», da una respuesta tan ambigua como consecuente: «Esta idea de overlapping consensus puede parecer esencialmente hobbesiana... pero la concepción de la justicia, es una concepción moral... da razón de las virtudes cooperativas idóneas a una doctrina política en vista de las condiciones y exigencias del régimen democrático... por tanto, el consenso resultante, tal como se considera allí (en A Theory of Justice) no se considera sólo un modus vivendi» (ibid. 249), sino que el punto de vista buscado y hallado se entiende como «punto de vista moral». Y se entiende así, porque tal concepción es la que mejor permite plasmar la autocomprensión contenida en la cultura pública de las sociedades democráticas.

Pero, ¿no podría ser quizá verdadera la «nueva teoría económica de la sociedad»? Sí, parece responder Rawls, lo mismo que quizá puedan ser también verdaderas las doctrinas del intuicionismo, de Kant o de Mill, pero la teoría de la justicia evita entrar en la discusión, no versa sobre eso. Pero, cabría replicar, la teoría de la justicia no puede evitar esa cuestión, pues no pocos miembros de las sociedades democráticas pueden muy bien entender el supuesto «punto de vista moral» como un modus vivendi. Es cierto, parece responder Rawls, al igual que otros lo aceptarán «porque sus creencias religiosas o la comprensión de su fe los llevan a un principio de tolerancia y suscriben la idea fundamental de la sociedad como un sistema de cooperación» (Rawls 1985, 250) y lo mismo que otros lo aceptarán porque están convencidos de que «se siguen de doctrinas ético-políticas tales como las de Kant y Mill», que ellos dan por sentado que están en lo cierto, y otros aún, sencillamente porque entienden que $A$ Theory of Justice «expresa valores que en el caso normal han de quedar por encima de todos los demás valores que se le opongan». Y es que en definitiva, esta fundamental condición de disenso de la existencia humana «puede tener también su lado bueno» (Rawls 1980, 542). Pues, «aunque una sociedad bien ordenada es una sociedad dividida y pluralista, sus ciudadanos han alcanzado, no obstante, un entendimiento acerca de los principios que regulan las instituciones básicas. Aunque no pueden llegar a un acuerdo sobre todo, el acuerdo público sobre cuestiones de justicia política y social sirve de sostén a lazos de amistad civil y asegura los lazos de la asociación» (ibid. 540).

Pero, ¿qué permite a Rawls suponer que es posible llegar a tal entendimiento? La respuesta de Rawls es: un duro aprendizaje histórico. «Hasta las guerras de religión ... la cooperación social sobre la base del mutuo respeto se consideraba imposible con personas de otras creencias; o con las personas que sustentaban una concepción distinta del bien. Una de las raíces históricas del liberalismo fue el desarrollo de diversas doctrinas que urgían la tolerancia religiosa. Un tema de la teoría de la justicia es recoger entre las llamadas «circunstancias subjetivas de la justicia» las condiciones sociales de esas doctrinas y después desarrollar las implicaciones del principio de tolerancia» (Rawls 1985, 249) (1982, 17). A la objeción de si esto no es, en definitiva, convertir esas circunstancias en filosofía, Rawls responde: «Una concepción de la persona desde un punto de vista político, por ejemplo, la concepción de los ciudadanos como personas iguales y libres, no implica, a mi juicio, cuestiones de psicología filosófica o de doctrina metafísica acerca de la naturaleza del self. Ninguna doctrina política que dependa de estos 
profundos e irresueltos asuntos puede regir como concepción pública de la justicia de un estado constitucional democrático» (Rawls, 1985, 231). Y si se le hace a Rawls la réplica obvia, la respuesta no puede ser más consecuente: «Cabría decir que desarrollar una concepción política de la justicia sin presuponer o utilizar explícitamente una doctrina metafísica, por ejemplo, alguna concepción particular matafísica de la persona, es ya presuponer una tesis metafísica: a saber, la de que para tal fin no se requiere ninguna doctrina metafísica particular. Cabría también decir que nuestras concepciones cotidianas de las personas como unidades básicas de deliberación y responsabilidad, presuponen y en cierto modo implican ciertas tesis metafísicas sobre la naturaleza de las personas como agentes morales y políticos. Siguiendo mi método de evitación simplemente no niego tales cosas... (debe ser verdad que hay incluidas tesis metafísicas, pero deben ser tan generales, que no distinguen entre puntos de vista metafísicos específicos -cartesianos, leibnizianos, o kantianos; realistas, idealistas, o materialistas, de los que se ha venido ocupando la filosofía tradicional)» (Rawls, 1985, 240).

En suma, la filosofía política posible para Rawls, en un régimen constitucional democrático, no ha de tratar tanto de fundamentar el principio de tolerancia, para eso ha llegado tarde, como de «aplicárselo a sí misma» (Rawls). No ha de presentarse con la pretensión de «filosofía política» verdadera, que es indiferente que sea, sino con la pretensión de «filosofía política» política, que importa que sea. Pues «el objetivo es el libre acuerdo, la reconciliación a través del razonamiento público» (Rawls, 1985, 230) y para ello «han de evitarse cuestiones filosóficas disputadas, al igual que cuestiones religiosas o morales disputadas... La teoría de la justicia deliberadamente se mantiene en la superficie, filosóficamente hablando» (ibid. 230). ¿Y si tal acuerdo, podríamos replicar a Rawls, no se asentase en realidad sino sobre un magnífico background error acerca de la naturaleza metafísica y moral del hombre? Es inútil volver a empezar, pues la contrarréplica de Rawls sería: las respuestas a esa cuestión serían controvertidas y no podrían constituir base de acuerdo. Por otro lado, insistimos en la cuestión de que una filosofía política así planteada elude la cuestión de relativismo o no relativismo. Si alguna vez los miembros de las (otrora) sociedades democráticas, llegaran a tener convicciones (aun respecto al principio de tolerancia) completamente insensibles al libro de Rawls, simplemente el libro no les diría nada, en nada contribuiría a la tarea de dar expresión institucional a la comprensión que tendrían de sí.

Es difícil aceptar este planteamiento de Rawls; sorprende la fusión de pesimismo teorético (a todos los efectos) y de optimismo político, o más bien, teórico-político, que el libro rezuma. La combinación de ambos no parece haber alcanzado aún el estado de «reflective equilibrium» que Rawls tanto invoca. Mas esto, claro es, no es tanto una objeción como una consideración piadosa. Pero pese a ser sólo una consideración piadosa, podemos darle una forma que nos indique la vía de una posible objeción. «No son las ideas, sino los intereses, venía a decir Weber, los que mueven la acción de los hombres, pero las concepciones del mundo, que están hechas de ideas, sirvieron en no pocas ocasiones de agujas, que determinaron las vías por las que la dinámica de los intereses movió la acción». En determinadas «circunstancias (históricas) subjetivas de la justicia» entre otras muchas circuns- 
tancias, se impusieron ideas que configuraron lo que podemos llamar la cultura pública de las sociedades democráticas. Ahora bien, el mundo de las ideas está trabado por nexos de sentido ante los que ineludiblemente se plantea la cuestión de su verdad o su falsedad, o mejor, de su validez o no validez, sea ésta veritativa, práctica o estética. Rawls parece conceder con optimismo y largueza la posibilidad de erigir un marco de razonamiento ético-político compartido en que los ciudadanos de las sociedades democráticas puedan allanar con imparcialidad sus diferencias sobre el modo de dar forma institucional a su autocomprensión, pero se muestra cicatero a la hora de admitir la posibilidad de un insightfull aprendizaje compartido a la hora de justificar metaética o metapolíticamente, como pretende la filosofía moral contemporánea, el marco erigido. La necesidad de erigir ese marco se basaría, por el contrario, en la experiencia sorda y ciega adquirida en determinados avatares históricos, de que, en definitiva no es posible compartir (supuestos) aprendizajes en esa dimensión. El valor del pensamiento ético-político de la Ilustración no radicaría tanto en sí mismo como en la elaboración que llevó a cabo de la experiencia de las guerras de religión. A mi juicio, esto no es conceptualmente consecuente, ni tampoco fue históricamente el caso. En este aspecto, sí me siguen pareciendo superiores los planteamientos de teoría ética que están lejos de compartir esos supuestos; más a veces los supuestos de que éstos, a su vez, han de partir, son tan pretenciosos, que no puede menos de resultar atrayente un planteamiento como el de Rawls, cuando se despoja terminantemente de todos ellos y, tras dejar a un lado toda «deep philosophical question», propone un marco de razonamiento, a lo menos análogo al que proponen aquellos. La razón de la analogía es clara: Rawls, sin revalidarlas, hace una propuesta de explicitación de las ideas que aquellos empiezan revalidando y que en ese proceso de revalidación no pueden menos de pasar a reformular. Empero, entre un marco teórico diseñado para tal revalidación y reformulación y otro que parte de esas ideas como «prejuicios», es decir, «as given», las diferencias tienen que ser decisivas. Ignorarlas en la práctica, en un intento de proyectar al segundo sobre el primero, sólo puede dar lugar a un baile de confusiones. Si a estas confusiones se añaden las resultantes de proyectar la evolución de Rawls sobre un único plano, el baile de confusiones se transforma en laberinto. Y me parece que la autora del artículo que vengo comentando a veces hace poco por no entrar en él.

\section{6. «Tarea social práctica» y filosofía trascendental}

Acerca del «afán de Rawls de construir una filosofía moral» (pág. 129), de que «la autonomía es para Rawls el prius indiscutible» (pág. 131), de que «frente al subjetivismo práctico y la verdad práctica, Rawls asume una tercera postura: la filosofía puede descubrir la objetividad moral» (pág. 134) no hacen falta más precisiones, porque ya hemos oído hablar de ello al propio Rawls. Pero sí conviene entrar en alguna precisión acerca del adjetivo añadido al término «objetividad», la cual a la autora se le transforma en «objetividad moral»; y no nos interesa tanto tan nimia cuestión como otras de más tomo que se enredan con ella. 
A lo largo de todo el artículo a la autora parece preocuparle especialmente que quede claro que no somos miembros fácticos de las sociedades democráticas quienes elegimos los principios de la justicia, «no es lo nuestro, dice, ni conocer intuitivamente los principios ni aprobarlos por mayoría» (pág. 131); a veces, esta insistente idea adquiere rasgos algo pintorescos: «Rawls distingue normas de principios, deja la elección de las normas en manos de los ciudadanos y se ocupa desde la filosofía de los principios justificadores de normas» (pág. 133); digo «pintorescos», porque, aparte de que tras concluido el aquelarre de la «posición original» y tras empezar a levantarse el «velo de ignorancia» Rawls acompaña todavía a las «partes» un buen trecho, el dejar la cuestión de los principios a «la filosofía» en nada remediaría, me temo, habida cuenta de que la filosofía la hacen filósofos, la arbitrariedad e inmoral desbarajuste que de la elección de los principios por mayoría se teme la autora. Los ciudadanos de Atenas tuvieron el acierto de no permitir que los principios se les diesen servidos «desde la filosofía». Por fin el problema queda en que «si la autonomía significa autolegislación, ¿Cómo la autolegislación individual puede desembocar en ley universal? El problema consiste, pues, en conectar autolegislación individual e intersubjetividad... nunca la autonomía kantiana o rawlsiana se redujo a la expresión de las convicciones morales de los individuos» (pág. 139). Y continúa: «Y es que en la tradición ética, la objetividad moral, la validez práctica de una norma, ha exigido siempre un momento de idealidad. La voluntad general, el espectador imparcial ... o la posición original integran limitaciones ideales a la pura facticidad (pág. 139). Y son esas condiciones ideales que el diseño de la «posición original» integra, las que «aseguran la objetividad de los resultados (= concordancia con la sensibilidad de los miembros de las sociedades democráticas en torno a la justicia)» (pág. 139). Y es que «Rawls apuesta por la justificación práctica que -siguiendo al filósofo de Königsberg- pretende objetividad práctica, no objetividad ni verdad teórica.

Pues bien, si la «objetividad», la «objetividad moral», la «validez práctica», la «objetividad práctica» del resultado que el momento de idealidad asegura, consiste en que ese resultado concuerda con nuestros «prejuicios», flaco momento de idealidad es ése; porque entonces la autonomía rawlsiana se reduce, en efecto, a ser «expresión de las convicciones morales de los individuos», a no ser que «convicciones morales de los individuos» no sea igual a «sensibilidad de los miembros de las sociedades democráticas», lo cual sería en verdad sorprendente. Aquí hay, pues, algo que dista mucho de estar claro. Para intentar aclararlo, acojámonos a la distinción entre norma y principio, que la autora subraya, por ver si llegamos a alguna parte.

Empecemos primero con la «elección de los principios por mayoría». La preocupación de la autora es ociosa. Si lo que Rawls busca es contribuir a superar el «impasse» a que ha llegado nuestra historia política contemporánea, consistente en que no hay acuerdo sobre a qué principios ha de responder el diseño de las instituciones sociales para que traduzcan la comprensión que tenemos de nosotros como seres morales libres e iguales, y lo que con ese fin hace es proyectar una construcción que razonablemente articule esa autocomprensión, para ver si se puede llegar a un acuerdo, es claro que «no es lo nuestro ni conocer intuitivamente los principios ni aprobarlos por mayoría». Sencillamente porque, por ventura o desventura, una autocom- 
prensión cultural, una cultura pública política, o incluso la idea que un individuo tiene de sí, caen entre lo que se adquiere con el tiempo o con el tiempo cambia (entre otros factores quizá, porque llega a verse que algunos de sus ingredientes son indefendibles), pero difícilmente podría entenderse que caigan entre las cosas que se deciden. Si Rawls logra articular esa autocomprensión en términos que permitan un acuerdo sobre la traducción de tal autocomprensión a principios que puedan reflejarse en instituciones básicas, A Theory of Justice ha cumplido la «tarea social práctica» en que consiste la filosofía política, está justificada prácticamente, ha cumplido su fin, ajustándose en efecto, a nuestra autocomprensión compartida, «es objetiva». Pues es entonces cuando por vía de la construcción que refleja a esa autocomprensión, se han llegado a obtener dos principios que constituyen criterios para decidir sobre la validez de los haces de expectativas normativas de comportamiento en que (además de en otras cosas) las instituciones básicas consisten; entonces tenemos el marco para enjuiciar esas normas; y esas normas, a la luz de aquellos principios, resultan legítimas o ilegítimas, lo que podemos considerar sinónimo de: tienen validez práctica (insistamos: de Stevenson en adelante hemos aprendido que una norma no puede equipararse a un enunciado, el cual es susceptible de verdad $=$ validez teórica) o no la tienen, lo que a su vez podemos considerarlo equivalente a: tienen «objetividad moral» o no son «moralmente objetivas». Si nos atenemos a esa distinción entre norma y principio, nuestra autora parece tender a confundir la adecuación de la construcción, que tiene su medida en si ésta resulta «congenial» (afín) a las «convicciones y a las tradiciones más profundamente arraigadas de un estado democrático moderno» (Rawls, 1982, 14), o en si «estas ideas y principios pueden combinarse con suficiente claridad en una concepción de la justicia política que se ajuste a nuestras convicciones más firmemente mantenidas» (Rawls 1985, 228), firmemente mantenidas, claro es, «on due reflection» (o en lo que he llamado «equilibrio reflexivo») (ibid.) confunde, digo, esta adecuación, llamándola «objetividad moral» con la cuestión de la validez práctica de una norma, validez que tiene su medida en si la norma se ajusta o no a los principios. El objeto de justificación práctica o el objeto de la tarea social práctica en que la tarea de la filosofía política consiste es la erección del marco de razonamiento éticopolítico; y es en ese marco donde se discute sobre la legitimidad o no legitimidad, sobre la validez o no validez de las normas.

Pero esta confusión tiene su raíz en un buen deseo. A los miembros de las sociedades democráticas que se dedican a filosofía del derecho, moral y política les gustaría saber si cuando hablamos de que una norma es legítima o de que es ilegítima, hablamos en serio o no. Para ello, naturalmente, hay que considerar la norma a la luz del principio o los principios de que disponemos; de modo que la cuestión se convierte en la de la validez de los principios o metanormas, o (cuando tales principios no coinciden con el procedimiento mismo [Habermas]) en la cuestión de la justificación del procedimiento de obtención de los principios. Es decir que, últimamente, de lo que se trata es de justificar el «punto de vista» desde el que procedemos a juzgar acerca de la validez de las normas. Mas como Rawls lo único que nos ha dicho es que el punto de vista que A Theory of Justice adopta, se acomoda a, o traduce (mejor que otras propuestas), convicciones profunda- 
mente arraigadas y éstas no se han revalidado, en la «posición original» no puede haber más «momento de idealidad» que cimente la objetividad moral, que el que pueda provenir de esos «prejuicios», es decir, bien poco. Esta es la objeción de Tugendhat: «La propuesta de Rawls de que podemos definir algo como justo si y sólo si se corresponde con los principios que para este tipo de cosas se estableciese en la posición original es una petitio principii y oculta el hecho de que la adecuación moral de la posición original ha de valorarse desde el punto de vista de la etapa cero» (Tugendhat, 1984, 30), etapa cero que, dicho aproximadamente, viene a consistir para Tugendhat en la revalidación de esos «prejuicios» en el contexto de lo que Rawls llamaría «a general moral conception» (Rawls 1985, 225). Y Habermas: una propuesta como la de Rawls «que se extiende a ámbitos de contenido, no puede entenderse sino como una aportación a un discurso que habrían de realizar los ciudadanos» acerca de qué exigir a la ordenación de las instituciones básicas; la teoría de Rawls sólo resultaría aceptable si pasase la prueba de tal discurso práctico (cuyas características resultan para Habermas de la revalidación de las convictions de las que Rawls parte «como dadas» (Habermas, 1983, 104).

Pues bien, lo que Rawls pretende es que este tipo de objeciones no aciertan con el punto en que radica la originalidad de su planteamiento, con aquello que le lleva a exigir que la filosofía política hoy «ha de mantenerse en la superficie, filosóficamente hablando». Pues supongamos que la tesis de Rawls fuera que tenemos un razonable concepto de «objetividad moral». La objeción, por ejemplo, de Tugendhat es que eso no es un razonable concepto de objetividad moral. El primer movimiento (method of avoidance) de Rawls es que una filosofía política que deliberadamente quiere mantenerse en la superficie evita ese tipo de cuestiones, en la medida en que sea posible. La réplica es que esa es una cuestión que no es posible evitar y que además demuestra que la filosofía política no puede mantenerse en la superficie, filosóficamente hablando. La dúplica de Rawls es que esto a su vez es una «deep philosophical question», que hay que tratar de evitar para el objeto de la filosofía política hoy. Y evitada así la cuestión, estamos de nuevo en la tesis inicial. Pero el objetor puede aún sostener que esa primera tesis inicial es en definitiva una tesis sobre la validez práctica. Respuesta de Rawls: «siguiendo el método de evitación no niego tal cosa, la evito». Parafraseando a Rawls: «Evito la cuestión de la validez práctica y la controversia entre «objetivismo moral» $\mathrm{y}$ «subjetivismo cultural» acerca del status de los valores morales. $\mathrm{Ni}$ afirmo ni niego estas tesis» (Rawls, 1985, 230).

La única duda posible entonces es la de si este «método de evitación» es en verdad tan mortal para el posible objetor que pretenda contra Rawls que una filosofía política que no se presente con «a claim of truth», no se tiene en pie; que una filosofía política que se presente sólo como «una tarea social práctica» es inviable. Si el método de evitación no da para tanto, $\mathrm{Tu}$ gendhat tiene razón en su objeción: nos es preciso una teoría de nuestro sense of justice, sense of justice cuya realidad se queda siempre en Rawls en una suposición formal, sin pasarse nunca a escudriñar su estructura; pero si el principio de evitación logra eludir esas objeciones, la única objeción que veo posible es la que se sigue de la precisión de la consideración piadosa que hice más arriba. 
Pero ante la dificultad que acabo de exponer, A. Cortina opta por reabsorber a Rawls no ya en la reformulación de Kant que representa la filosofía moral contemporánea atenida al «programa de Hare» sino en el propio Kant, oscilando a la vez entre el Kant de la «Fundamentación de la Metafísica de las Costumbres», pues de optar decididamente por éste, la tarea de la fundamentación de una concepción moral se le hubiera convertido en una tarea epistemológica (en suma, la de como es posible el juicio sintético a priori en que se expresa el imperativo de la moralidad) y el Kant de la «Crítica de la Razón Práctica», quien desesperando de la vía tomada en el tránsito del libro segundo al libro tercero de la Fundamentación, muda de método y parte en la Crítica de que «la razón pura es por sí sola práctica (es decir, somete al ser racional a otras reglas que las determinadas por los deseos y apetencias de éste) y da al hombre una ley general que llamamos ley moral», como de un «factum innegable», que «no es un hecho empírico, sino el único factum de la razón pura, la cual con ello se anuncia como originariamente legisladora (sic volo, sic iubeo)» (Kant 1929, 36-37). Este hecho es indicación de un mundo nouménico, en que se articula nuestro destino como seres morales; ese mundo es noche cerrada para nuestra capacidad de penetración intelectual, pero dado nuestro interés práctico, que ese mismo hecho determina, y utilizando ese mismo factum como «principio de deducción» podemos asegurarnos (für wahr halten) de aquello que si en actitud teorética quisiésemos penetrar, convertiría a nuestra teoría en expresión de un delirio (cual fue el de las imágenes míticas y religioso-metafísicas del mundo), indefendible ante el tribunal de la propia razón; todo lo cual podría sonar (puestos, desde luego, denodadamente a recordar) a algo de lo que Rawls quiere decir con «justificación práctica».

Claro es que para nosotros, desde que la razón se nos presenta revestida de lenguaje, no tenemos más remedio que recurrir al factum del lenguaje, susceptible, por supuesto, de análisis teorético, también en punto (parece) a sus implicaciones atinentes a las reglas del discurso práctico. Y así es natural que las reformulaciones contemporáneas de la ética kantiana hayan mirado más, incluso cabría decir que exclusivamente, a la Fundamentación que a la Crítica; y de la «Fundamentación de la Metafísica de las Costumbres», sólo un paso permitiría recordar (a condición, de nuevo, de ponerse denodadamente a recordar) lo que Rawls entiende por «tarea (social) práctica», precisamente el que Kant rechaza en la Crítica (Kant, 1946, 113 y Kant 1929, 36, «El factum de la razón -dice en este último lugar no se puede sacar de cavilaciones tontas (herausvernünfteln) acerca de la conciencia de la libertad»).

Pues bien, el intento de reabsorber a Rawls en Kant, o de proyección de Rawls sobre Kant, lleva a la autora a algunas equiparaciones que merecen comentario.

Pero antes conviene corregir algunas pequeñas imprecisiones en que a mi juicio se incurre en el artículo, pues su acumulación no nos permitiría ver al cabo nada. El equilibrio reflexivo es, naturalmente, para Rawls, un estado (Rawls 1973, 49) y un estado, naturalmente, no es un método ( $« \mathrm{El}$ método de justificación rawlsiano -el "equilibrio reflexivo"-...») (pág. 134); a renglón seguido, el estado, convertido en método de justificación se convierte a su vez en justificación («La justificación práctica de Rawls viene 
constituida por el equilibrio reflexivo ...») (pág. 134). Ese «equilibrio reflexivo» convertido en método trata de explicitar lo que ya está implícito en la conciencia de los miembros de las sociedades democráticas, de modo que concuerden en ello» (pág. 134); pero es difícil ver cómo un estado, aunque se lo convierta en un método de justificación, devenido él mismo justificación, puede tratar de explicitar nada. Aparte de eso, la autora habla de que lo que Rawls toma como punto de partida es «el momento en que queda objetivada nuestra conciencia moral, el momento en que quedan plasmadas nuestras "convicciones meditadas"» (pág. 134), cosa que es difícil de entender al no decírsenos en qué consiste ese momento, y que quizá se ve mejor si decimos simplemente que en nuestras convicciones meditadas se plasma nuestro sentido de la justicia, nuestra conciencia moral, sin que ello, desde luego, prejuzgue cuáles de esas plasmaciones se fundan en razón y cuáles no, pues nuestras facultades no son precisamente infalibles cuando proceden a plasmarse.

Esta serie de imprecisiones quizá podrían disiparse si planteáramos las cosas así: El problema que Rawls afronta viene constituido por el «impasse que se ha producido en nuestra reciente historia política, a saber: que no hay acuerdo acerca de cómo habría que ordenar las instituciones sociales básicas para que se conformen a la libertad e igualdad de los ciudadanos como personas» (Rawls, 1982, 20). La resolución del problema define el objeto de la teoría política; el método «es elaborar una concepción que sea congenial con nuestras convicciones y tradiciones más arraigadas del moderno estado democrático» (ibid. 14), que trate, pues, de suturar los puntos de desacuerdo estribando en las convicciones comunes a que los distintos bandos apelan; cuando la construcción está hecha o se está haciendo, nuestras convicciones tienen un espejo, en que al verse reflejadas pueden también autocorregirse o corregir la construcción; se produce un vaivén entre convicciones y construcción especular hasta conseguir un estado de equilibrio (siempre inestable); es lo que Rawls llama equilibrio reflexivo. Cuando se alcanza dicho equilibrio, si es que llega a alcanzarse, la construcción está justificada.

Me temo que la autora convierte al «equilibrio reflexivo» en método en un intento de encontrar en algún lado en Rawls el método de la reflexión trascendental de Kant. Pero en el contexto de ese intento resulta que «el "factum de la razón" no es (para Rawls) la conciencia del imperativo, sino los juicios meditados, los juicios que emitimos en condiciones favorables al ejercicio de la justicia» (pág. 134). Esto, precisamente, no es hacer justicia ni a Kant ni a Rawls. En la Fundamentación, Kant parte de nuestros juicios meditados, pero pasa (libro segundo) a «un análisis de la lógica de nuestros conceptos morales». «Estos conceptos y su lógica determinan... ciertas reglas a las que hemos de obedecer en nuestro pensamiento si queremos hacerlo racionalmente» (Hare), es decir, a una teoría de nuestro sense of justice, ante la que, en efecto, nuestros juicios meditados se muestran «prestos a afrontar la reflexión crítica». Pero esto es en la actualidad lo que he llamado el «programa de Hare» y no hace falta repetir que nada tiene que ver con el de Rawls. Decir que el «equilibrio reflexivo», «como la reflexión trascendental de Kant, parte de un factum y trata de explicitar sus condiciones normativas de posibilidad» (pág. 135), si nos estamos refiriendo al procedimiento de Kant en la Fundamentación, es una galana manera de malinter- 
pretar tanto a Kant como a Rawls; y si nos estamos refiriendo al procedimiento inverso de que Kant hace uso en la Crítica de la Razón Práctica, significaría que las deep-seated convictions and traditions del estado democrático moderno representan para Rawls algo suficientemente análogo a «la conciencia de un imperativo como factum de la razón», de «un factum único de la razón pura que con ello se anuncia como originariamente legisladora», del que la construcción explicitaría «sus condiciones normativas de posibilidad» (pág. 135), lo cual me parece un exceso a la hora de referirse a las mencionadas deep seated convictions and traditions, y sobre todo a la hora de traducir la idea de Rawls de que la construcción models (sirve de modelo de y para) esas convicciones.

Claro es que la autora puede argumentar que solamente se trataba de una reabsorción metafórica de Rawls en Kant, pues por lo que Rawls en realidad opta, lejos de todo factum de la razón, es por el «relativismo histórico» (pág. 144). Mas entonces es difícil entender cómo Rawls «apuesta» también «por la justificación práctica que -siguiendo al filósofo de Königsbergpretende objetividad práctica, y no verdad ni objetividad teórica» (pág. 144) ni como, a la vez (el lector tiene derecho a empezar a preguntarse: ¿en qué quedamos?) puede optar por una fundamentación empírica (el tipo de fundamentación al que la autora dice atenerse Tugendhat en sus Retractaciones), cuando una hipótesis empírica lo único que puede pretender es verdad y objetividad teórica. Puede que hayamos de quedar en que la fundamentación de Rawls es «empírico-práctica». Pero obsérvese que tal caracterización, conforme a las propias explicaciones de la autora, habría de reunir notas contradictorias: por lo de «justificación práctica», no puede pretender llegar a enunciados verdaderos, sino «moralmente objetivos»; por lo de empírica, se supone que ha de pretender llegar a resultados «verdaderos». Pienso que es inútil seguir señalando pasos en este laberinto. Pero quizá sí convenga pedir ayuda a Rawls para que nos devuelva al menos al punto de partida. En un pasaje paralelo al que alega la autora para calificar la teoría de Rawls de empírica, dice éste: «En orden a elaborar una concepción kantiana de la justicia parece deseable desligar la estructura de Kant de su trasfondo de idealismo trascendental y darle una interpretación procedimental por medio de la construcción de la posición original. Ese desligamiento es importante aunque sólo sea porque nos faculta para ver hasta qué punto es posible una interpretación de las ideas de Kant dentro de un marco de referencia razonablemente empirista» (Rawls 1978, 67).

\section{Consistencia y adecuación}

Hasta aquí he supuesto dos cosas, la consistencia interna de la construcción revisada de Rawls (I) y que esa construcción traduce en efecto, las deep-seated convictions and traditions de un estado democrático moderno (II). Antes de concluir, quisiera al menos apuntar que tales cosas no pueden darse sin más por sentadas.

(I) A las partes en la posición original se las supone dotadas de racionalidad económica, lo que quiere decir que por definición se orientan en sus cálculos a la consecución de lo que consideran su bien. En A Theory of Justice el «velo de ignorancia» que caracterizaba a la situación en que se llevan 
a efecto los cálculos de utilidad aseguraba que el resultado del cálculo de cada uno fuera el resultado a que llegaban todos, pues cada uno, por fuer$\mathrm{za}$, ha de ponerse, para calcular su bien, en el lugar de todos; cuando se habla de intersubjetividad en la «posición original», no puede tratarse sino de una forma metafórica de hablar. Para poder dar sentido a la idea de cálculo, se introducía una lista de «bienes primarios» cuya estructura no se razonaba. Y para interpretar el «aceite» de este cálculo, podía recurrirse al «agua» de Kant; es decir, se añadía una «interpretación kantiana de la posición original», que era sólo eso, una interpretación que evocando tradiciones éticas hacía plausible que la construcción tuviera en definitiva algo que ver con algo así como nuestro sense of justice. Las recetas para mezclar el agua y el aceite quedaban en consideraciones vagas que en rigor no abordaban el problema de la compatibilidad (Rawls 1973, 251 ss.).

Pero cuando en «El Constructivismo Kantiano»y en «Las libertades Básicas y su Prioridad» la noción de cooperación entre personas morales libres e iguales entra como concepción-modelo dentro de la propia construcción, las cosas cambian. A las personas se las supone dotadas de dos capacidades morales, la de desarrollar un efectivo sentido de la justicia («La capacidad de entender, aplicar y actuar por mor de -y no sólo conforme alos principios de justicia» (Rawls 1980, 525)) y la de «formar, revisar y perseguir racionalmente una concepción del bien» (ibid. 525), de los correspondientes dos «intereses supremos» de realizar y ejercitar esas capacidades y del «interés superior» de desarrollar la particular concepción del bien que les acontezca tener una vez levantado el velo de ignorancia. La, «posición original» es ahora una concepción-modelo puente entre la noción de cooperación social entre personas morales libres e iguales y la obtención de los principios de justicia, los cuales sustentan la tercera concepción-modelo, la noción de «sociedad bien ordenada», «el ideal a realizar en la vida social».

Pues bien, como para obtener los principios de justicia no puede renunciarse a la teoría de la decisión racional (con esa renuncia la teoría de Rawls se desvanecería), surge el problema de que si convertimos a las personas dotadas de esos dos intereses supremos en habitantes de la posición original, no tenemos más remedio que considerarlas como egoístas racionales cuyos cálculos se orientan a la consecución de lo que consideran su bien. El caso es que el segundo interés moral supremo, el relativo a las concepciones del bien, puede aún caer bajo la razón de bien, pues la capacidad de desarrollar una concepción del bien puede concebirse como parte integrante del sistema de fines por el que oriento mi vida: puede que no me merezca la pena ningún sistema de fines si no soy yo mismo el que asumo la responsabilidad de adoptarlos, revisarlos o rechazarlos. Ahora bien, el segundo interés supremo, el interés por desarrollar un sentido de la justicia, no puede caer bajo la razón del bien. Pues si no se introduce el supuesto adicional de que las personas son estoicas e identifican el bien con la virtud, ello supondría que no buscan fair terms of cooperation por mor de ellos mismos, sino por el bien que de ellos pueda seguirse; luego esa parte de la construcción es incompatible con la primera concepción modelo. Veamos el origen de la incompatibilidad.

En «El constructivismo kantiano» Rawls comete el error de suponer que 
las personas pueden ser los habitantes de la «posición original»: «Así, en la posición original podemos concebir a las partes, o bien como representantes (o delegados) de las personas con ciertos intereses, o bien como esas mismas personas movidas por esos intereses (los dos intereses supremos)» (Rawls 1980, 525). Pero al percatarse en ese mismo pasaje de que las «partes», como egoístas racionales que son, lo que por definición calculan es la obtención de bienes, aunque aquí se trate de bienes primarios, se limita a huir el cuerpo a la dificultad con una consideración edificante: «Pero a la base del deseo de bienes primarios están los intereses supremos de la personalidad moral y la necesidad de asegurar su particular concepción del bien (interés superior)..., por tanto, la suposición de que las partes se preocupan de asegurar sus propios intereses supremos no puede confundirse con el egoísmo» ( ibid, 578). Pero Rawls sabe muy bien que la incompatibilidad entre la primera concepción modelo y la segunda estriba, no en la clase de intereses, sino en la razón bajo la que la distinta noción de racionalidad obliga a considerar esos intereses, la cual, por cierto, borra las diferencias de clase entre intereses. A. Cortina, menos cauta que Rawls a la hora de formular esa idea, y sin percatarse de que Rawls no afronta la dificultad, incurre de lleno en el otro cabo de la misma inconsistencia: «Los móviles de la deliberación son, pues, morales, aunque «egoístas» en el sentido de que cada jugador defiende sus propios intereses. Los propios intereses piensa Rawls, no tienen por qué ser inmoralmente egoístas» (pág. 141). Lo cual es cierto, sólo que para hacer tal afirmación hemos de contar ya con principios morales antes de haberlos obtenido por la vía del procedimiento que estamos construyendo; se diría que estamos trabajosamente construyendo una escalera para subir donde ya estamos.

En «Las libertades básicas y su prioridad» Rawls se desdice de la forma en que en «El constructivismo kantiano» conectó las dos concepcionesmodelos e intenta una solución que a mí me parece no exenta de bizantinismo. En la segunda concepción-modelo, en la posición original, dice, «hay que distinguir cuidadosamente dos partes distintas,... las partes como representantes racionalmente autónomos de las personas en la sociedad bien ordenada, representan sólo lo racional (la capacidad de las personas para perseguir racionalmente una concepción del bien)... lo razonable o capacidad de las personas para un sentido de la justicia queda representado por las distintas restricciones a que las partes quedan sujetas en la posición original» (Rawls, 1982, 19-20). Es decir, que los habitantes de la posición original no son las personas, sino egoístas racionales que las representan, es decir, unos agentes artificiales cuya razón de ser es permitirnos hacer uso del instrumento que es la teoría de la decisión racional. Los dos elementos de la primera concepción-modelo, de la concepción de la persona, separados en la segunda, quedan otra vez reunidos en los habitantes de la sociedad bien ordenada. «Son los ciudadanos iguales en una sociedad bien ordenada los que son plenamente autónomos (los que reunen lo racional y lo razonable) porque aceptan libremente las ligaduras de lo razonable y al hacerlo así su vida política refleja una concepción de la persona, que considera fundamental su capacidad (de ellos) para la cooperación social, es decir, para un sentido de la justicia» ( ibid. 20). 
Con esta reordenación de elementos queda, en efecto, evitada, al menos a primera vista, la inconsistencia que hemos señalado; pero a mi entender, esa inconsistencia vuelve a aparecer en los mismos términos en otra parte. En efecto, las partes sólo pueden considerar los intereses supremos de las personas que representan, bajo la razón del bien que la realización y ejercicio de esos intereses representan para ellas. De modo que cuando, por ejemplo, escogen como primer principio de justicia «Toda persona tiene igual derecho a un esquema plenamente adecuado de libertades básicas que sea compatible con un similar esquema de libertades para todos», lo escogen, no porque el principio defina fair terms of cooperation (que los define, dadas las condiciones en que ha sido escogido, es decir, en una situación sometida a las ligaduras de lo racional), sino «porque creen que si las personas actúan por mor de tal principio (y no sólo conforme a él), ello servirá como medio efectivo para el desarrollo de las concepciones del bien de las personas que representan» (Rawls, 1982, 30) (y ahora debe corregirse el paréntesis anterior: los principios definen fair terms of cooperation por las condiciones en que han sido escogidos y porque las partes encontraron razones para tal creencia, pues, de otro modo, por construcción, la tarea de definir fair terms of cooperation, hubiera resultado insoluble, no hubiera sido posible obtener principios de justicia).

Tenemos, pues, que los ciudadanos de las sociedades bien ordenadas actúan, no sólo conforme a los principios de justicia, sino por respeto a los principios de justicia. Mas no se les plantea nunca en términos dramáticos el conflicto entre bien y deber, y ello porque unos seres artificiales se encargaron de averiguar la armonía preestablecida existente entre utilitarismo/perfeccionismo y deontologismo, de suerte que si tal armonía no se diese los principios respetados no serían esos, serían otros o no serían ningunos (si la tarea de las partes hubiera resultado insoluble). Los ciudadanos de las sociedades bien ordenadas, naturalmente, no saben esto, pero a nosotros que hemos visto proceder a las partes no me explico cómo tales principios pueden merecemos tal respeto como para actuar por mor de ellos mismos, sobre todo cuando, dado lo que Rawls entiende por una concepción del bien («Una concepción del bien consiste normalmente en un determinado esquema de fines y metas, y de deseos de que florezcan ciertas personas y asociaciones en tanto que objeto de nuestras vinculaciones y lealtades. Una concepción del bien incluye también una visión de nuestra relación con el mundo -religiosa, filosófica y moral- por referencia a la cual entendemos aquellos fines y vinculaciones» (Rawls 1982, 16), es muy posible que tengamos nuestro corazón en otra parte. Supuesto cualquier concepto de igualdad, aunque sea el de Hobbes, y el esquema de libertades básicas de Rawls como parte integrante de nuestras, según Rawls, inconmensurables concepciones del bien, no veo que el planteamiento de Rawls diste una micra del utilitarismo de la norma. No es mi intención entrar aquí en este tema, pero, en cualquier caso, en un planteamiento que pretende implicar tan radical diferenciación respecto del utilitarismo y en el que a propósito de la elección de los principios puede decirse, aunque sea por coacciones dimanadas de la construcción, que «nótese que en ningún punto el razonamiento de las partes se ocupa del desarrollo y ejercicio del sentido de la justicia por mor de él mismo; aunque por supuesto eso no es verdad de los ciudadanos plenamente autónomos en 
la sociedad bien ordenada» (Rawls 1982, 34), hay algo «que no está bien filtrado» y que bien podría radicar en lo siguiente: en cuanto la construcción recoge en sí lo que en A Theory of Justice no era más que una interpretación, se torna inconsistente; en cuanto trata de reparar la inconsistencia, se torna utilitarista y se le vuelve indiferente aquella interpretación ${ }^{2}$.

(II) «Una sociedad -dice Rawls- es una empresa cooperativa para mutua ventaja, y viene típicamente marcada, así por un conflicto como por una identidad de intereses... Por tanto se necesitan principios para escoger entre estos diversos ordenamientos sociales que determinan esta división de ventajas y para suscribir un acuerdo acerca de qué haya de considerarse distribución justa. Tal necesidad define el papel de la justicia» (Rawls 1972, 126). ¿Y si nos negamos a admitir algo aparentemente tan simple? ${ }^{3}$.

Para ver qué se sigue de tal negación, consideremos el «Segundo Libro sobre el Gobierno» de Locke como primera formulación de la tradición liberal y el libertarismo de Nozick como radicalización de esa tradición (prescindencia del contrato, atenida a los propios supuestos de la tradición liberal). Y consideremos «El Contrato Social» de Rousseau como primera formulación plena de la tradición democrática. Rawls representaría, como él mismo dice, un intento de mediación entre esas dos tradiciones, pero desde el marco de la tradición democrática; el propio Rawls parece bien consciente de ello.

Consideremos ahora los choques históricos entre ambas tradiciones y también los compromisos entre ellas. La tradición liberal surge como reacción al estado absolutista; su finalidad es poner límite al ejercicio de un poder, del que desconfía siempre, pero al que, reducido a un mínimo, considera, empero, imprescindible. Limitado constitucionalmente el poder por los «lockean rights» (estado de derecho) y legitimado por su funcionalidad en una sociedad que se organiza sobre la base de esos derechos, que incluyen el derecho de propiedad sobre los medios de producción, el liberalismo se promete un orden social, además de justo, estable, introduciendo el supuesto (dogma liberal y dogma de la economía política clásica) de que el resultado agregado de las acciones justas (las que no violan los derechos lockeanos de nadie) se estabiliza por sí solo. Este orden social es capaz de traer a la luz las capacidades individuales más insospechadas, que un orden centralmente regido jamás podría poner en juego (Hayek).

El problema de la tradición democrática, en cambio, es históricamente el de la estructura del poder que el liberalismo limita. La imagen básica de esa tradición es la de la asamblea de ciudadanos, a disposición de la cual queda todo lo atinente a la vida del colectivo. Las resoluciones que, en relación con la ordenación de esa vida, en la asamblea se toman son justas si

2 O al menos no se ve cómo pueda bastar a destacar «las diferencias respecto al punto de vista utilitarista, el cual toma el bien (subjetivo) como noción independiente y primera y define lo correcto o justo (right) en términos de maximización de ese bien y por tanto como subordinado a él» (Rawls, J., «Social Unity and primary goods» Sen, A./Wiliams, B. (eds.) Utilitarianism and Beyond, C. U. P. 1982.

3 Cfr. sobre lo que sigue: Habermas, J., Theorie des Kommunikativen Handelns, tomo II, Consideraciones Finales; C. B. Mcpherson, The Life and Times of Liberal Democracy, Oxford 1977; A. Giddens, National State and Violence, London 1985. 
son resultado de un proceso de deliberación que cumple determinadas condiciones (una de ellas, por ejemplo, es que todos puedan hablar y decir libremente lo que piensan sobre el problema de que se trate; algunas de esas condiciones se solapan, pues, con los derechos de la tradición liberal. Cuando ese solapamiento no se produce, estilizando mucho podemos decir que, análogamente a como antaño el estado absolutista, el estado democrático queda cercado por los derechos liberales (estado democrático de derecho). La primera manifestación de compromiso entre ambas tradiciones de pensamiento político es la «Declaración Universal de los Derechos del Hombre y del Ciudadano» de 1789, cuyo título como es sabido, se debió a un fundamental desacuerdo expreso entre diputados inspirados por Locke y diputados inspirados en Rousseau.

En concreto, entre el orden económico liberal asentado sobre principios juridificados de la tradición liberal y la autocomprensión democrática del Estado se establece una persistente relación de tensión, sobre todo, cuando históricamente quedo claro que el resultado agregado de las acciones individuales atenidas a los principios liberales juridificados no se estabiliza por sí mismo, sino que se hace menester, para mantener la estabilidad de la sociedad civil, que el liberalismo había considerado aproblemática, la intervención del Estado, democráticamente legitimado, en el ciclo económico, y la compensación, por vía de derechos reconocidos, de las vicisitudes que en contra del supuesto liberal, el orden liberal de la esfera del trabajo se muestra incapaz de absorber; es el estado de derecho democrático y social.

Tanto la obra de Rawls como la obra de Nozick aparecen en el instante en que el Estado benefactor, el contemporáneo compromiso histórico entre las tradiciones liberal y democrática empieza a hacerse inviable por razones funcionales. En la obra de Nozick se niega a Rawls algo que éste parece tomar como algo obvio: que la estructura básica de la sociedad es el objeto primero de la justicia. «El papel de las instituciones que pertenecen a la estructura básica es asegurar estas condiciones justas de fondo en el marco de las cuales tienen lugar las acciones de los individuos y asociaciones. A menos que esta estructura esté apropiadamente regulada y ajustada, un proceso social, inicialmente justo, puede dejar en un momento de ser justo, por más free and fair que puedan parecer las transacciones particulares cuando se las mira en sí mismas» (Rawls 1978, 53). Pues bien, ni para la tradición liberal ni para la tradición liberal radicalizada existe tal background justice que prejuzga la justicia o injusticia de las formas de comportamiento ejercidas en su marco. Sólo puede llamarse justa a la estructura social, cualquiera que sea y por más «desagradable» que pueda resultar a un espectador, que «resulte» de comportamientos justos. Cuando en «The Basic Structure as Subject», Rawls, tras describir el planteamiento de Nozick trata de enfrentarse a él, en realidad lo elude: «Empezaré señalando, dice, algunas consideraciones que nos llevan a mirar la estructura básica como objeto primero de la justicia, al menos cuando procedemos dentro del marco de a kantian social contract theory», lo que para Rawls viene a significar: dentro del marco de la tradición democrática. Pero entonces, si la suposición básica es que bajo la competencia de la asamblea de ciudadanos cae la regulación de la vida colectiva, sobre todo en sus aspectos centrales, y ello en un proceso de deliberación sometido a determinadas condiciones que aseguren que los re- 
sultados de las deliberaciones definan, en efecto, fair terms of cooperation, sí es verdad que la basic structure es el objeto primero de la justicia; mas esto es una tautología, no una respuesta a la tradición liberal radicalizada.

Ahora bien, el libro de Nozick articula un concepto de mónada moral «free and equal» que también es trasunto de deep seated convictions and traditions de los estados modernos y que, al prescindir del concepto de sociedad como empresa cooperativa, nada tiene en absoluto que ver con lo que la construcción de Rawls articula, en la que la «overarching fundamental intuitive idea» (Rawls 1985, 231) es la de la sociedad como un fair system of cooperation entre personas morales libres e iguales.

Naturalmente, no se trata aquí de proceder a una comparación entre Rawls y Nozick, sino de lo siguiente: la teoría de Rawls pretende articular una concepción de la justicia social y política que sea congenial con las deep seated convictions and traditions de un estado democrático moderno, convicciones y tradiciones a las que toma como dadas. Pues bien, cabe sospechar, ante el libro de Nozick, que esas tradiciones y convicciones, cuando se las toma as given, resultan tan incompatibles que hacen imposible la filosofía política como la practica1 social task que Rawls quiere que sea. Para cumplir su tarea social práctica la filosofía política tendría que empezar siendo una empresa teorética de revisión, revaluación y de reformulación de las tradiciones que Rawls considera como dadas, y Rawls parece dar por sentado que la filosofía política no puede ser hoy tal cosa. Cabría concluir que entonces la filosofía política no es posible ni como «filosofía política»verdadera ni como «filosofía política» política. Y por tanto, si la obra de Rawls nutrió la ilusión de que por fin teníamos una filosofía política, quince años después cabe sospechar que ni hay ni puede haber tal filosofía política.

\section{Pero, ¿es posible aún una filosofía política?}

Mas hay desengaños de los que cabe aprender, y no poco. Pues, ¿cabía concebir en serio la ilusión de que fuera posible esa filosofía política situada por encima de las ciencias sociales o situada al lado de, pero nunca dentro de, las ciencias sociales? En un momento nos dice Rawls: «I suppose the society in question is closed» (Rawls 1982, 15). No es difícil reconocer aquí la autarkeia que en el esquema aristotélico de la política clásica se atribuye a la koinonia politiké frente a otras formas de koinonia englobadas en ella. En la «Filosofía del Derecho» de Hegel se rompe por primera vez con el esquema aristotélico de la política clásica que considera a la sociedad como república, seu societas civilis, seu communitas politica, esquema que se mantiene en pie hasta el propio iusnaturalismo moderno, cuyo contenido Rawls quiere reformular y cuya forma Rawls trata de resucitar. Hegel nos describe como característica de la modernidad social la emergencia de un orden social distinto del político, cuya descripción excede las posibilidades de aquel esquema. De la aporética de ese orden, por la que éste se ve llevado más allá de sí mismo hasta cerrar al mundo en un único sistema y de su relación con los órdenes estatales han de ocuparse, naturalmente, las ciencias sociales. Y dicho con simpleza, éstas, cuando aparte de describir, quieren enjuiciar lo que describen, incorporan en, y articulan con, sus supuestos teóricos supuestos normativos, que en algún señalado caso son los de la ética kantia- 
na contemporánea, con el fin todo ello de contribuir a hacerse cargo de la situación y alumbrar (ahí es nada) nuevas formas de vida satisfactorias y viables. «El ideal de una sociedad bien ordenada, escribe Rawls, presupone una teoría de la naturaleza humana, y en términos generales una teoría sociológica, pero la tarea de la doctrina moral es especificar una apropiada concepción de la persona que los hechos generales acerca de la naturaleza humana y de la sociedad permitan» (Rawls 1980,534). Pues bien, me temo que lo que las ciencias sociales empiezan no permitiendo es el esquema de pensamiento que Rawls utiliza en su filosofía política; quedó rebasado con mucho por las actuales circunstancias históricas de la justicia. Puede que la línea de pensamiento que va de Hegel-Marx a Giddens-HabermasWallerstein, por citar algunos nombres que ayuden a fijar lo que quiero decir, no tenga más perspectiva de éxito que la propia filosofía política de Rawls, pero lo que sí es cierto es que no consiente a su lado (si no es con carácter muy subordinado y a efectos sólo de practicabilidad; por ejemplo, a la hora de enjuiciar un determinado sistema jurídico como si fuese el de una sociedad cerrada) la forma de filosofía política a que se atiene el tipo de renovación del iusnaturalismo moderno que las obras de Nozick y Rawls, por citar dos ejemplos, representan. Es posible que hoy sólo quepa pensar en una filosofía política dentro de las ciencias sociales, es decir, como sociología crítica.

\section{BIBLIOGRAFÍA}

Habermas, J.

1983: Moralbewusstsein und kommunikatives Handeln, Frankfurt.

Hare, R.M.

1981: Moral Thinking, Oxford.

1984: «Liberty and Equality», en Social Philosophy and Policy, vol. 2, 1. Kant.

1946: Fundamentación de la Metafísica de las Costumbres (vers. García Morente), Madrid.

1929: Kritik der Praktischen Vernuft (ed. K. Vorländer, Phil. Bibliothek), Hamburg. Rawls, J.

1951: «Outline of a Decision Procedure for Ethics», Philosophical Review, 60, 1951. 1973: A Theory of Justice, Oxford.

1978: «The Basic Structure as Subject», en Goldman/Kim (ed.), Values and Moral, Dordrecht.

1980: «The Kantian Constructivism in Moral Theory», Journal of Philosophy 77. 1982: «The Basic Liberties and their Priority», Tanner Lectures on Human Values, Utah U. P.

1985: «Justice as Fairness: Political not Metaphysical», Philosophy and Public Affairs, vol. 14, 3 .

Tugendhat, E.

1984: Probleme der Ethik, Stuttgart

Jiménez Redondo, M.

1983: Constructivismo, Rawls, Nozick, Valencia.

En prensa ya este artículo, se acaba de publicar en castellano «Justicia como equidad. Materiales para una teoría de la justicia» (Tecnos, Madrid, 1986), con traducción y estudio introductorio de M. A. Rodilla. 